\title{
A Supply Chain Management View from ICPR - Innovation in Product and Production
}

\author{
Dieter Spath \\ Fraunhofer Institute for Industrial Engineering IAO, Stuttgart, Germany
}

\author{
Katja Klingebiel \\ University of Dortmund, Fraunhofer Institute for Material Flow and Logistics IMS, \\ Dortmund, Germany
}

\section{Sergio Eduardo Gouvea da Costa}

Pontifical Catholic University of Parana (PUCPR), Federal University of Technology (UTFPR), Curitiba, PR, Brazil

\section{Luiz Felipe Scavarda}

Pontifical Catholic University of Rio de Janeiro (PUC-Rio), Rio de Janeiro, RJ, Brazil

\begin{abstract}
This Special Issue of the Brazilian Journal of Operations and Production Management (BJOPM) features six papers selected from the Supply Chain Management (SCM) track of the $21^{\text {st }}$ International Conference on Production Research (ICPR), which conference theme was "Innovation in Product and Production". This introduction paper evaluates and summarizes the selected contributions characterizing SCM with a leading role in innovation management. The research presented here focuses on supply chain design and cultural influences on supply chain performance, bridges the gap between basic research and industrial application and provides approaches to effectively design supply networks and processes. Some of the dominate key topics emphasized in the six papers contained in this special issue are countertrade in supply chains, types of contracts in supply chains, Value Stream Mapping (VSM), process management, supply chain performance measurement, order penetration points and inventory policies for distribution systems. The main research tools used are Analytical Hierarchy Process (AHP), simulation, SCM logistic scorecard and Markov chains.
\end{abstract}

Keywords: Supply Chain Management, Countertrade, Contract, Supply chain performance, Value stream mapping, Order penetration point, Inventory policy.

\section{Introduction}

The $21^{\text {st }}$ International Conference on Production Research (ICPR), held in Stuttgart, Germany, has again encouraged communication among researchers in the fields of production development, production systems and processes, as well as 
promoted research in the fields of production research and industrial engineering. This time the conference has been shaped around the megatrends and topics that will drive innovation in the next decades: energy, environment, health, mobility, communications and security. This Special Issue of the Brazilian Journal of Operations \& Production Management (BJOPM) brings together some of the most significant papers presented at the ICPR track entitled Supply Chain Management.

The term SCM was introduced in the early 1980's (Oliver and Webber, 1982 apud Christopher, 1992). Since then it has been receiving attention of managers, consultants and researchers, thus, it cannot be considered a new field of research (Romano, 2003). However, interest in SCM is growing, as evidenced by the number of papers recently published on different aspects of the subject. Figure 1 presents the number of papers retrieved based on a selected search using the Emerald and ScienceDirect (Elsevier) databases (in groups of three years). In pseudo code, the phrase "supply chain management" was used within the journal abstracts. The search returned 1,935 papers. The growing number of publications on SCM peaks in the last and more recent group (from 2009 to 2011).

Key innovations are necessary to initiate new industrial and social stages of development. Consequently, research in supply chain management shall be driven by the idea to actively shape the future of supply networks. Nevertheless, for SCM to behold

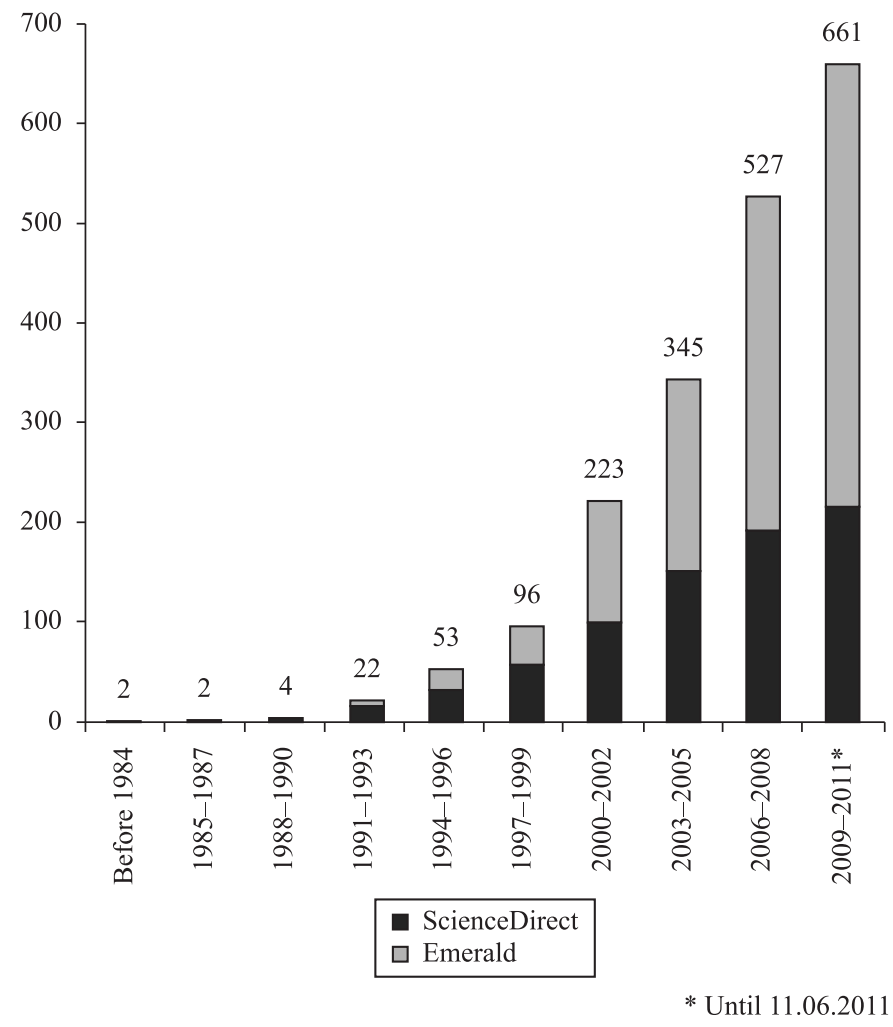

Figure 1. Growing number of publication on SCM (papers from Journals). 
its leading role in innovation management not only evolutionary but also revolutionary approaches are needed. Research is asked to uncover the social significance of these approaches and vice versa to incorporate the influence of society and its individuals on SCM. Influencing factors comprise business strategies, market trends, political objectives and statutory provisions as well as technological innovations. Thus, the research presented in this special issue focuses on supply chain design and cultural influences on supply chain performance, bridges the gap between basic research and industrial application and provides approaches to effectively design supply networks and processes. Next, this editorial paper summarizes the respective articles conducted by researchers from different countries and institutions: Austria (Vienna University of Technology and Fraunhofer Austria Research), Germany (Fraunhofer Institute for Material Flow and Logistics, Technical University of Dortmund and University of Westfälische Wilhelms), Switzerland (University of St. Gallen), Brazil (Methodist University of Piracicaba and Pontifical Catholic University of Rio de Janeiro), Mexico (University of Guadalajara), and Japan (Akita Prefectural University, Hiroshima University and Tokyo Institute of Technology).

\section{Overview of the Special Issue Articles}

The exploratory research conducted by Hofmann, "Compensation and buy-back deals in supply chains: analyzing strategic decision areas by using AHP”, highlights the phenomenon of countertrade in supply chains and takes first steps towards the conceptualization and explanation of a potentially powerful competitive tool-the analytic hierarchy process (AHP) - in practice. While research in countertrade has been limited in the recent past, practice has re-invented the use of reciprocal deals to structure SCM. Hofmann's article helps to close this gap and to both advance theory on the current use of countertrade as well as to inform practice on the range of objectives a countertrade might help to achieve. The purpose of the research from an academic perspective is to shed light into the forms and drivers of countertrade to conceptualize and explain this phenomenon in supply chains today. As results, the network perspective has been identified as an appropriate lens to study the reciprocal relationships that countertrade builds upon. Generic types of countertrade were identified from a theoretical perspective to define its variants as a suggestion to the field of SCM research. The motivations and drivers of supply chain actors to participate in countertrade were distilled and synthesized in a multiple-criteria decision making model to further specify an extensive, yet succinct set of major business objectives. The resulting list of business objectives for countertrade is a contribution to further research in countertrade and contributes to the discussion of reciprocal arrangements in supply chains, in general. The decision model based on AHP has been used to shed light into the drivers behind a specific form of countertrade. The application of the model demonstrated how specific motivations of an actor influence the choice, and hence, the existence of a specific form of countertrade in supply chains. In addition, the AHP application also illustrated how external factors could influence the form of the phenomenon in a specific supply chain structure. From a practical perspective, the purpose is to specify the phenomenon of countertrade in supply chains today and explain the involvement of firms into its specific forms.

Gomez Padilla and Mishina's article, "Comparison of the performance of a supply chain under rebate and option contracts", compares the performance of the companies forming a dyadic supply chain, and for the chain as a single unit, under 
these two types of contracts. A rebate contract is considered in their research as oriented to encourage the retailer to increase his stock, as the supplier offers the retailer an advantageous price if he orders a bigger quantity. With an option contract, the supplier shares the variation on demand risk as the supplier fixes a price for the units and both, retailer and supplier, agree on an option premium (sum to be paid to the supplier when the final order is modified). The performance is measured in economic terms (benefits and costs) and in physical units (inventory held and unsatisfied demand). In order to compare the performance of the contracts, several situations are simulated for one retailer and one supplier from a supply chain. The situations differ on the values given to the parameters. From one simulation to another two elements are modified: the pricing scheme (the rebate) for rebate contract and the conversion rate for option contract. The simulation results helped to identify which is the better contract for a given set of parameters. A rebate contracts increases the benefit for the chain as well as the gains for retailer and supplier. With a rebate contract the retailer passes bigger orders because the base stock is higher; the retailer increases his sales (and gains more) because he has more stock to face demand, and the supplier increases his sales (and gains more) because the retailer orders bigger quantities. From the results of simulation, it is also possible to conclude that a rebate contract is more convenient for the retailer in terms of backorder cost reduction. The insights of this research show that offering rebates based on a target may increase the benefit for the chain and that even though the trends are toward zero stock policies, increasing the inventory may lead to increase the benefit because there are enough units to satisfy demand; what is particularly important when the market is a lost sales one. The results also point out that rebate contract is better because the retailer pays less for the units; while in the option contract the retailer will always pay more. This leads to identify that further research should be done considering different rebate schemes, other conversion rates, and different holding stock prices to identify when a rebate contract stops being more advantageous. Different demand patterns should be also considered.

A group of researchers from the Vienna University of Technology and from Fraunhofer Austria, lead by Wilfried Sihn, bridge the gap between basic and applied research in their article "Utilizing a process management approach to standardise the application of value stream mapping" (Kuhlang, Edtmayr, Sunk, Morawetz and Sihn). Originating from the Toyota Production System, Value Stream Mapping (VSM) as a paper and pencil tool provides transparency over organizational value streams by application of a four-step approach. As antipole to the pragmatic VSM approach, the generic Process Life Cycle with its four phases is presented as a generic approach to systematic processes management. By comparing both approaches strong similarities emerge: both first phases mark the scope of process improvement. Also both second phases focus on analysis of the as-is and both third phases on the design of the to-be; nevertheless the different approaches apply different techniques and tools in these two latter phases. In both approaches phase four is centered on the implementation of planned future processes. Despite these overlaps, the presented Process Management life cycle follows the principle of continuous improvement in terms of business processes reengineering, whereas VSM is commonly applied for selected improvements of individual processes. Consequently, by systematic embedding of Value Stream Mapping into the life cycle of Process Management a stronger standardization of VSM is possible; thus linking the successful VSM techniques to business processes reengineering and introducing a new VSM life cycle of innovation management and continuous improvement. Nevertheless, now this new basic theory needs to be verified and validated in applied in research projects. 
In contrast to this basic research, the article of Gong, Ogasawara and Suzuki "Supply chain operational performance and its influential factors" empirically analyzes significant success factors to operational supply chain performance in China and Japan. As starting point for improvement of supply chain efficiency, supply chain performance measurement provides those performance measures which drive strategic business improvement. Consequently, the authors focus on the respective correlation of these elements manifested in the performance measurement instrument "SCM Logistics Scorecard (LSC)". The LSC is well suited for relationship analysis of supply chain performance and managerial-technical orientation. The 22 integrated criteria of the SCM Logistics Scorecard are divided into four fundamental groups covering as different aspects as corporate strategy, planning capability, logistics performance and IT methods. In a 5 year LSC data collection process, a cross national comparison of 554 Japanese enterprises with 236 Chinese organizations reveals the impact of cultural differences as well as of foreign ownership on international supply chain performance. Furthermore, with the organization originating from nearly all industry branches including food, electronics, automotive, chemistry, fiber and pharmaceutical, the influencing factors on operational supply chain performance could be identified and correlated to financial indexes. Interestingly, it could be identified that in many aspects Chinese and Japanese business strategies resemble each other more than expected: for example the interrelation between supplier collaboration and information technology is seen in both countries similar but differently as in other countries. By help of these empirical findings best practices and vice versa also cultural and individual weaknesses in supply chain strategies are subject to identification. Nevertheless, the scope of research needs to be extended further from Japan and China to the leading, emerging and developing international countries.

The research conducted by Klingebiel, Hellingrath, Pires, and Scavarda, "Integrated design and evaluation of logistic networks: oriented placement of the order penetration point", offers a method for the Order Penetration Point (OPP) positioning under a supply chain perspective, integrating the influence of product diversity and supply chain flexibility over a complete product life-cycle systematically. This research is supported by the BRAGECRIM program, a German-Brazilian collaborative research initiative on manufacturing technology. The proposed method may assess the impact of design options for involved upstream and downstream processes as all influencing factors can be integrated into the simulation-based assessment. Criteria for involved upstream and downstream processes can be integrated freely. The article analyzes the implications of OPPs using the automotive industry as the object of study.

The research group of the Hiroshima University dedicates their research to inventory policies in distribution systems, as offered in the article: "An inventory control policy with tracking information for dual-channel supply chains" from Nagao, Takahashi, Morikawa and Hirotani. As one of the most important logistical drivers, inventory plays a significant role for the supply chain's performance. Inventory policy decisions have a huge impact on the efficiency and responsiveness of a supply chain. While distribution gets more and more complex, for example by introduction of several distribution channels, additionally, global networks have to deal with long lead times and transports that are prone to risks and disruptions. Thus, it is imperative to integrate real-time information, e.g. tracking information, as well as dynamic and stochastic behavior into inventory planning. The research of Nagao et al. applies the theory of Markov chains to inventory policy, i.e. to optimize order quantity and point. The underlying model takes into consideration customer demand and behavior, long and uncertain replenishment lead times, tracking 
information and costs for dual-channel supply chains. The developed policies can reduce the cost of exceptional replenishment and transports thus contributing to the objectives of resource-and energy-efficiency of supply chains.

\section{Final Remarks}

The co-editors believe that the six papers of this special issue provide an interesting contribution to innovation and research in supply chain management by offering a broad look at challenges and key innovations that occupy the minds of practitioners and academic researchers. Taken together, the papers constitute stimulating reading for different audiences in the fields of production research and industrial engineering. Members of the ICPR, readers of the BJOPM and SCM scholars will find new perspectives, alternative research methods and new empirical contexts into different research areas of Supply Chain Management.

\section{Acknowledgements}

The co-editors of this special issue would like to thank the support and incentive of Dr. Helder Gomes, editor-in-chief of the Brazilian Journal of Operations and Production Management, Dr. Vagner Cavanaghi, the president of the Brazilian Association for Industrial Engineering (ABEPRO), the International Foundation for Production Research (IFPR) and especially its publications committee chaired by Prof. C. O'Brien. The development of this special issue would not have been possible without their involvement. The co-editors also acknowledge the grateful help from the several special issue reviewers, who are top scholars from a diverse set of disciplines related to the area of Supply Chain Management. Finally, the co-editors are particulary indebted to the authors of the six papers who have expended huge effort in following and respecting the stringent deadlines.

\section{References}

Christopher, M. (Ed.) (1992). Logistics - the strategic issues. London: Chapman \& Hall. Romano, P. (2003) Co-ordination and integration mechanisms to manage logistics processes across supply networks. Journal of Purchasing \& Supply Management, Vol. 9, pp. 119-134. http://dx.doi.org/10.1016/S1478-4092(03)00008-6

\section{Biography}

Prof. Dr.-Ing. Dieter Spath is an international renowned researcher in the field of technology management. After his work as director at an international corporate group, Professor Spath headed the Institute of Machine Tools and Production Science at the University of Karlsruhe. Since 2002 he is director of the Fraunhofer Institute for Industrial Engineering IAO in Stuttgart and of the Institute for Human Factors and Technology Management IAT at the University of Stuttgart. Professor Spath is part of the committee of the National Academy of Science and Engineering (acatech Munich). $\mathrm{He}$ is considered as a vehement advocate of innovation for our economy under integral consideration of human factors, organization and technology.

Contact: dieter.spath@iao.fraunhofer.de 
Katja Klingebiel is head of the Research Center for Logistics Assistance Systems at the Fraunhofer Institute for Material Flow and Logistics in Dortmund, Germany. She studied applied mathematics and obtained her Doctoral Degree (Dr.Ing.) at the Faculty of Mechanical Engineering, Technische Universität Dortmund. She worked several years at the University of Dortmund as a researcher and later postdoctoral fellow, in automotive consulting and for the Fraunhofer Institute for Material Flow and Logistics. She has managed several national and international research projects and she is responsible for the key topic "Logistics-as-a-Service" in the German LeadingEdge Cluster Effizienzcluster LogistikRuhr. Her areas of expertise especially comprise supply chain management, order management and business process reengineering.

Contact: katja.klingebiel@iml.fraunhofer.de

Sergio Gouvea da Costa is Professor of Operations Management at the Industrial and Systems Graduate Program at the Pontifical Catholic University of Parana (PUCPR), and Associate Professor at the Federal University of Technology- Parana (UTFPR) - Brazil. He holds a BSc. degree in Electrical Engineering from UTFPR, a MSc. degree in Electrical Engineering (Automation) from the State University of Campinas, and a PhD. in Industrial Engineering from the University of Sao Paulo. During his PhD. he was a Visiting Fellow at the Institute for Manufacturing, University of Cambridge, UK. During 2009/2010 he was a Visiting Professor at the Edward P. Fitts Department of Industrial and Systems Engineering at North Carolina State University, USA. He is a Board Member (2010-2013) of the Society for Engineering and Management Systems of the Institute of Industrial Engineers (SEMS/IIE), USA, and a Board Member and Secretary-General (2011-2013) of the International Foundation for Production Research (IFPR). His current research interests include manufacturing strategy and performance, AMT adoption, lean and sustainable operations. He has published in several international journals, including the International Journal of Production Economics, Journal of Manufacturing Technology Management, and Measuring Business Excellence, among others.

Contact: s.gouvea@pucpr.br

Luiz Felipe Scavarda is Professor at the Industrial Engineering Department of PUC-Rio. His Graduate, Master, and Doctoral degrees in Industrial Engineering were obtained at PUC-Rio. His areas of expertise are in the field of supply chain management. During 2000/2002 he joined as visiting researcher the German Fraunhofer Institute for Manufacturing Engineering and Automation and in 2009 he was a post-doctoral fellow at the Vienna University of Technology. He has published in several international journals (e.g. International Journal of Operations \& Production Management and International Journal of Production Economics).

Contact: lf.scavarda@puc-rio.br

\section{Article Info:}

Received: December, 2011

Accepted: December, 2011 